* Mestre em Ciência Jurídica pela Universidade do Vale do Itajaí (UNIVALI) com período sanduiche na Universidade do Minho. Bacharel em Direito pela Fundação Universidade Regional de Blumenau (FURB). Email: calaj1831@ gmail.com

**Doutorado Interdisciplinar em Ciências Humanas em andamento pela Universidade Federal de Santa Catarina (UFSC). Doutor em Direito pela Universidade Federal de Santa Catarina (UFSC). Mestre em Ciência Jurídica pela Universidade do Vale do Itajaí (UNIVALI). Especialista em Direito Sanitário pela Fundação Osvaldo Cruz (FIOCRUZ). Especialista em Direito Civil, Direito Negocial e Imobiliário pela Universidade Anhanguera (UNIDERP). Especialista em Direito Notarial e Registral pela Universidade Anhanguera (UNIDERP). Especialista em Direito Penal e Processual Penal pela Universidade do Vale do Itajaí (UNIVALI). Especialista em La Regulación y Aplicación de los Tributos pela Universidad Castilla La-Mancha. Especialista em Direito Tributário pela Universidade do Sul de Santa Catarina (UNISUL). Aperfeiçoameto em Curso Preparatório a Magistratuda pela Escola da Magistratura do Paraná (EMAPAR). Aperfeiçamento em Curso Preparatório para Ingresso na Carreira pela Escola Superior do Ministério Público do Paraná (FEMPAR). Aperfeiçoamento em Direito pela Associação dos Maistrados do Trabalho da $9^{\mathrm{a}}$ Região (AMATRA). Graduado em Comunicação Social Jornalismo pela Universidade Estadual de Ponta Grossa (UEPG). Bacharel em Direito pela Universidade Estadual de Ponta Grossa. Email: zenildo@univali.br

\section{A Sustentabilidade Empresarial Como Critério \\ NORMATIVO à EFETIVIDADE DO INSTITUTO DA RECUPERAÇÃO JUDICIAL}

\author{
Business Susteinability as a Normative Criterion to \\ THE JUDICIAL RECOVERY COMPANY ENTERPRISES
}

\section{Clarice Ana Lanzarini* Zenildo Bodnar**}

Como Citar: LANZARINI, Clarice Ana. BODNAR, Zenildo. A sustentabilidade empresarial como criterio normativo à efetividade do instituto da recuperação judicial. Scientia Iuris. Londrina, v.24, n.1, p. 124-141, março 2020. DOI $10.5433 / 21788189.2020 v 24 n 1 p 124$. ISSN 2178-8189.

Resumo: O presente trabalho pretende analisar o instituto da recuperação judicial de empresas à luz da sustentabilidade. Para tanto, inicialmente realiza uma abordagem histórica do direito falimentar à recuperação judicial de empresas no Brasil. Na sequência, discorre sobre o caminho percorrido pelo desenvolvimento sustentável em direção à sustentabilidade empresarial. Por fim, são expostas ideias e ponderações para identificar se a sustentabilidade se afigura como critério normativo à efetividade dos instrumentos recuperacionais de uma empresa em cenário de crise. Neste artigo, utiliza-se o método de abordagem indutivo, método de procedimento hipotético e pesquisa bibliográfica. Como resultado da pesquisa foi possível constatar que recuperação de empresas e sustentabilidade contemplam o bem-estar coletivo como norte comum, logo, caminham no mesmo sentido, e contribuem ampla e mutuamente com o desenvolvimento socioeconômico das empresas e da sociedade como um todo.

Palavras Chave: Recuperação judicial. Sustentabilidade. Sustentabilidade empresarial.

Abstract: This paper aims to analyze the institute of the business judicial recovery based on sustainability. To this end, it initially takes a historical approach to the bankruptcy right to a business judicial recovery in Brazil. It then discusses the path taken by sustainable development towards corporate sustainability. Finally, ideas and considerations are presented to identify whether sustainability appears as a normative criterion for the 
effectiveness of a company's recovery instruments in a crisis scenario. It uses the inductive approach method, the hypothetical procedure and bibliographic research techniques. The results allow us to realize that corporate recovery and sustainability both contemplate collective well-being, move in the same direction, contributing broadly and mutually to the socio-economic development of companies and of the society as a whole

Keywords: Judicial Recovery. Sustainable Development. Sustainable Company. 


\section{INTRODUÇÃO}

As empresas são fundamentais ao progresso da sociedade, eis que criam empregos, incentivam o desenvolvimento tecnológico, geram tributos, produzem bens e serviços imprescindíveis à satisfação das necessidades humanas. Neste sentido, tem-se que o fenômeno da globalização propiciou o surgimento de grandes empresas, as quais, economicamente, apresentamse mais fortes do que muitos países. Hoje, certas empresas transnacionais podem interferir em questões econômicas, ambientais e sociais de maneira mais incisiva e direta do que muitos chefes de Estado.

Todavia, hodiernamente, com um cenário econômico complexo, muitas empresas se encontram em crise, notadamente financeira, sendo grande o número daquelas que não conseguem superar suas dificuldades, deixando de honrar seus compromissos e acabando por encerrar suas atividades.

Isto posto, ressalta-se que a quebra traz consigo consequências avassaladoras de toda ordem: perde-se uma fonte produtora de bens e serviços; gera-se desemprego, com reflexos que ultrapassam a pessoa do trabalhador, pois produzem também degradação ambiental, resultado da deterioração do parque fabril e do tratamento inapropriado dos resíduos industriais, por exemplo. São reflexos econômicos, sociais e ambientais que comprometem o desenvolvimento da comunidade em que a empresa se encontrava inserida.

É preciso, pois, que sejam criadas ferramentas para mitigar e até prevenir o fenômeno do encerramento das atividades empresariais. Nesta senda, entra em cena o instituto da Recuperação Judicial, que busca a manutenção da fonte produtora, dos empregos dos trabalhadores e dos interesses dos credores, promovendo a preservação da empresa, sua função social e o estímulo à atividade econômica.

A realidade, contudo, é que grande parte das empresas que buscam a Recuperação Judicial não logra êxito nesta empreitada. Assim sendo, a mera existência de mecanismos recuperacionais não é suficiente à revitalização empresarial. É preciso que ocorra uma mudança de paradigmas pelo empresariado que, conscientizando-se do importante papel desenvolvido pela empresa no cenário local, nacional e internacional, busque uma gestão eficiente, que não prejudique os pilares nos quais baseia seu soerguimento, gerando lucros, preservando a integridade ambiental e o bemestar para as gerações atuais e futuras.

É necessário que a postura da empresa também evolua, a fim de adequá-la aos novos tempos. Neste viés, tem-se a empresa sustentável, compreendida como aquela voltada não só aos resultados econômicos, mas também à promoção do desenvolvimento social e à preservação do planeta.

Assim, o presente artigo busca investigar se o êxito na utilização da Recuperação Judicial se relaciona à conduta sustentável adotada pela empresa. Para a pesquisa, foram levantadas as seguintes hipóteses: a) a capacidade de soerguimento, condição indispensável à obtenção dos benefícios legais de recuperação de uma empresa em crise, encontra-se intrinsecamente ligada à 
ideia de sustentabilidade; b) o desenvolvimento sustentável é o caminho para uma empresa superar uma crise econômico-financeira.

Quanto à metodologia empregada, registra-se que, tanto na fase de investigação (PASOLD, 2015 , p. 87) ${ }^{1}$ quanto na fase de tratamento de dados, foi utilizado o método de abordagem indutivo (PASOLD, 2015, p. 91) e o método de procedimento hipotético e pesquisa bibliográfica.

\section{EVOLUÇÃO DO DIREITO FALIMENTAR À RECUPERAÇÃO DE EMPRESAS NO BRASIL: BREVE ESCOÇO DO NECESSÁRIO}

Antes do atual panorama de recuperação de empresas, longo foi o caminho percorrido pela civilização para aperfeiçoar o tratamento concedido ao falido que, no início dos tempos, poderia ser aprisionado, escravizado e até morto pelo credor, caso não saldasse suas dívidas ${ }^{3}$. Revelandose injustas tais punições, começou-se a construir o entendimento de que, caso não houvesse agido com má-fé, poderia o comerciante ser auxiliado a superar suas dificuldades financeiras.

No Brasil, o primeiro regramento jurídico a tratar do assunto diz respeito às ordenações. As Afonsinas admitiam a cessão de bens, a fim de o devedor evitar a falência; já as Manuelinas estabeleciam que a falência do devedor sujeitava-o à prisão, até que honrasse os pagamentos, podendo ceder seus bens como forma de evitar a segregação (CLARO, 2009, p. 85); as Filipinas começaram a delinear o direito falimentar (REQUIÃO, 1993, p. 14) como figura penal (ARAÚJO, 2009, p. 15).

A peça chave do direito falimentar luso e colonial-brasileiro, contudo, desvinculado das ordenações, foi o Alvará de 13 de novembro de 1756, assinado pelo Marquês de Pombal. A partir daquele momento se reconheceram quatro tipos de impossibilidade de satisfação de compromissos pelos comerciantes: a) impontualidade: a falta de pagamento em dia; b) ponto: a parada total de pagamento; c) quebra: a impossibilidade de pagar as suas obrigações; d) bancarrota: a quebra fraudulenta, onde os culpados eram condenados como públicos ladrões (ARAÚJO, 2009, p. 15).

$\mathrm{O}$ referido documento fora extremamente rigoroso no que dizia respeito à falência fraudulenta, impondo aos insolventes castigos que já não mais se admitiam no processo falimentar: pena de morte, banimento para o Brasil ou, ainda, para outra colônia (ARAÚJO, 2009, p. 16). Por outro lado, o comerciante idôneo que caísse em insolvência sem ter concorrido para o evento (se sofresse perdas vultosas em alto mar, por exemplo), estaria isento de responsabilidade, entretanto, deveria se sujeitar a um procedimento especial, apresentando-se à Junta Comercial, confessando

1 " $[\ldots .$.$] momento no qual o Pesquisador busca e recolhe os dados, sob a moldura do Referente estabelecido [...]."$

2 "[...] pesquisar e identificar as partes de um fenômeno e colecioná-las de modo a ter uma percepção ou conclusão geral $[\ldots] "$.

3 O Código de Hamurabi (século XVIII a.C) previa o oferecimento de pessoas como garantias de dívidas. Entre tantas, cite-se a seguinte disposição: $\S 117$ Se uma dívida pesa sobre um awilum e ele vendeu sua esposa, seu filho ou sua filha ou entregou-se em serviço pela dívida: trabalharão durante três anos na casa de seu comprador ou daquele que os tem em sujeição; no quarto ano será feita sua libertação (BOUZON, 1976, p. 57). Já a Lei das XII Tábuas, no século V a.C, pregava a morte no caso de insolvência. É o que se extrai da Tábua III, segundo a versão de Ortolan, com a tradução de Sílvio Meira: Se são muitos os credores é permitido, depois do terceiro dia de feira, dividir o corpo do devedor em tantos pedaços quantos sejam os credores, não importando cortar mais ou menos (Tertiis nundinis partis secanto; plus minusve secuerint, ne fraude esto); se os credores preferirem, poderão vender o devedor (como escravo) a um estrangeiro, além do Tibre (trans Tiberium) (LIMA, 1983, p. 646-647). 
a falência e apresentando os livros obrigatórios, sob pena de tornar-se fraudulenta a quebra (REQUIÃO, 1993, p. 15).

Para Requião (1993, p. 15), o Alvará de Marquês de Pombal, constitui “o ponto de partida para o estudo da instituição falimentar no direito pátrio", ideia compartilhada por Claro (2009, p. 85), para quem "este regramento jurídico é considerado como o marco inicial do instituto da falência no ordenamento jurídico do Brasil".

A partir deste ponto, o instituto da falência no Brasil conheceu quatro fases importantes: a) a primeira fase corresponde a época do Brasil Imperial, quando restou editado nosso Código Comercial, em 1850. Em sua terceira parte, tratava "Das Quebras", dispondo sobre a falência e a concordata suspensiva da falência; b) a segunda fase, com o Brasil República, refletiu o desejo de compatibilizar o direito falimentar com o clamor social e político dos novos tempos. Assim, foi editado o Decreto $\mathrm{n}^{\circ}$ 917, de 24.10.1890, que reformou a parte do Código Comercial que tratava "Das Quebras" e introduziu a concordata preventiva; c) a terceira fase iniciou com a Lei $\mathrm{n}^{\circ}$ 2.024, de 17 de dezembro de 1908, que simplificou o mecanismo processual da lei, aperfeiçoou os princípios que informavam o Decreto $n^{\circ}$ 917/1890, corrigindo suas falhas; d) a quarta fase histórica da falência corresponde à edição do Decreto-Lei nº 7.661, de 21 de junho de 1945.

O Decreto-Lei $n^{\circ} 7.661 / 45$ refletiu, na época, a nova ordem mundial capitalista e o ideário nacional-desenvolvimentista, cujo objetivo era a criação de uma indústria moderna, mediante planejamento econômico e, principalmente, intervenção do Estado na economia e na própria sociedade organizada (CLARO, 2009, p. 87). Deu ênfase ao instituto da falência, permitindo a continuidade do negócio pelo falido e da concordata, tanto preventiva quanto suspensiva.

Machado (2007, p. 22) aponta que "raramente uma empresa em concordata conseguia sobreviver e, mais raramente ainda, uma empresa falida era capaz de desenvolver a continuidade de seus negócios". Os tempos modernos exigiam, portanto, um mecanismo mais aprumado aos rumos da economia mundial, fortemente influenciada pela globalização, objetivando, justamente, a preservação da empresa. Era necessário um instrumento com maior flexibilidade, que conferisse maiores oportunidades para a empresa superar suas crises.

Após uma longa tramitação no Congresso Nacional, veio à luz, então, a Lei no 11.101 , de 09 de fevereiro de 2005, que introduziu formalmente o instituto da recuperação judicial em nosso ordenamento jurídico. A nova lei refutou o objetivo liquidatório-solutório pelo qual se pautava a legislação anterior, que perdurou por seis décadas, apresentando novos mecanismos jurídico-econômicos "para que a empresa em crise possa buscar o soerguimento necessário à sua manutenção no mercado competitivo" (CLARO, 2009, p. 21).

$\mathrm{O}$ aparecimento de instrumentos destinados ao soerguimento de uma empresa em dificuldades financeiras resultou especialmente da consciência de que a falência envolvia outros interesses e atores, além dos interesses do devedor e de seus respectivos credores.

Tornou-se necessário, assim, introduzir um novo conceito acerca do instituto e do aprofundamento de seus objetivos perante os credores, o devedor e a própria sociedade. Nesse momento histórico do ordenamento jurídico brasileiro, a recuperação de uma empresa em crise 
não mais se limitaria à mera satisfação dos credores. Fazia-se necessário, ademais, "conservar a fonte produtora e resguardar o emprego, ensejando a realização da função social da empresa, que, afinal de contas, é mandamento constitucional” (FAZZIO JUNIOR, 2015, p. 119).

Daí porque, para Lobo (2009, p. 123-124),

[...] a recuperação judicial é o instituto jurídico fundado na ética da solidariedade, que visa a sanar o estado de crise econômico-financeira do empresário e da sociedade empresária com a finalidade de preservar os negócios sociais e estimular a atividade empresarial, garantir a continuidade do emprego e fomentar o trabalho humano, assegurar a satisfação, ainda que parcial e em diferentes condições, dos direitos e interesses dos credores e impulsionar a economia creditícia [...].

Portanto, é preciso que a empresa seja viável para que seja efetivamente recuperada e supere a crise econômico-financeira, sob pena de se transferir aos credores o risco da atividade. Significa dizer que a recuperação judicial deverá ser "capaz de restabelecer o curso normal das coisas, retornando o risco da atividade ao seu titular" (TOMAZETTE, 2014, p. 46). A viabilidade, por sua vez, "deve ser demonstrada no processo para que se possa conceder a recuperação judicial" (TOMAZETTE, 2014, p. 46). A superação da crise econômico-financeira é, desta feita, o objetivo primordial da recuperação judicial.

Em vista do panorama acima traçado, observa-se que o legislador enumerou, no artigo 47 da Lei n. ${ }^{o} 11.101 / 05$, os objetivos específicos da recuperação judicial, in verbis:

A recuperação judicial tem por objetivo viabilizar a superação da situação de crise econômico-financeira do devedor, a fim de permitir a manutenção da fonte produtora, do emprego dos trabalhadores e dos interesses dos credores, promovendo, assim, a preservação da empresa, sua função social e o estímulo à atividade econômica (BRASIL, 2005).

O saneamento dessa situação de crise, contudo, não pode ser tido como único intuito do legislador, afinal, a recuperação judicial "não é mera solução de dívidas e encargos. Tem em conta a concretização da função socioeconômica da empresa em todos os seus aspectos" (FAZZIO JUNIOR, 2015, p. 123).

Dentre os objetivos específicos previstos pelo legislador, destaca-se a manutenção da fonte produtora, ou seja, da própria empresa e da atividade por ela desenvolvida. Vale dizer que "o primeiro objetivo específico prevalece sobre os demais, é ele que deve pautar todas as medidas da recuperação judicial", na medida em que essencial em vista dos demais, considerados secundários (TOMAZETTE, 2014, p. 47).

Isto porque, na ação de recuperação judicial, conforme explica Fazzio Júnior (2015, p. 123-124), “o objeto mediato é a salvação da atividade empresarial em risco e o objeto imediato é a satisfação, ainda que impontual, dos credores, dos empregados, do Poder Público e, também, dos consumidores $[\ldots] "$ ". 
Ainda, Pacheco (2013, p. 2) afirma que:

[...] tendo em vista a multiplicidade de interesses na permanência, continuidade e preservação da empresa, na aplicação da lei que venha a incidir, na hipótese de estar o empresário ou sociedade empresária em crise econômico-financeira, devese atender aos fins sociais a que ela se dirige e às exigências do bem comum, nos precisos termos do art. $5^{\circ}$ da Lei de Introdução.

Por fim, exsurge da própria lei a fundamentação principiológica do instituto recuperacional, baseado na função social da empresa, sua preservação, na dignidade da pessoa humana e na viabilidade econômica. Neste sentido, o princípio da preservação da empresa possibilita a proteção dos "interesses sociais em benefício da comunidade, como forma de tutela dos direitos humanos, e, em particular, da dignidade da pessoa humana" (PERIN JUNIOR, 2009, p. 34). Trata-se, nos dizeres de Mamede (2006, p. 182), de "metanorma que é diretamente decorrente da anterior: é preciso preservar a empresa para que ela cumpra a sua função social".

No que tange ao princípio da dignidade da pessoa humana em relação ao da preservação da empresa, nos dizeres de Queiroz (2006, p. 7-20), "um princípio universal do direito, da economia e das ciências sociais é o de que o único núcleo de desenvolvimento econômico e social que existe é a empresa"; assim, além da prática do mero assistencialismo, é preciso "preservar a dignidade da pessoa humana mediante a manutenção da empregabilidade, alcançada com a preservação da célula social, bem público caracterizado sob a forma de empresa" (QUEIROZ, 2006, p. 15).

Com efeito, ao se preservar a empresa, preserva-se a dignidade da pessoa humana. Tais premissas devem ser observadas como sendo o

[...] princípio supremo da ordem constitucional e também como fim último da ordem econômica, exigindo que a atividade econômica contribua para a sua efetivação. Se a atividade econômica proporciona a indignidade, estará em desacordo com a Constituição Federal, impondo-se a ação restauradora do Estado e da sociedade (PERIN JUNIOR, 2009, p. 112).

Por fim, deve-se dizer que a manutenção de uma fonte produtora não deve ser defendida a qualquer custo, devendo ceder à sua inviabilidade econômica. Há um limite a ser observado na busca pela recuperação da empresa em crise: sua viabilidade econômico-financeira. Assim sendo, embora seja papel do Estado fornecer meios para que uma empresa em crise possa se recuperar, também configura atribuição estatal manter o mercado competitivo preservado:

Noutros termos, se de um lado existem os princípios da livre iniciativa e da livre concorrência, devidamente encartados na Constituição Federal, por outro lado há uma ilação lógica e inarredável de que esse mesmo empreendedor, que se aventura no mercado, tem inequívoca ciência de que poderá ser dele afastado caso não reúna as condições mínimas de se manter na competitividade (CLARO, 2009, p. 177). 
Para Fazzio Júnior (2015, p. 16), ainda que se considere a importância que exerce a atividade econômica organizada no bojo de uma sociedade pluralista e de livre iniciativa, "sempre é aconselhável ter em mente o desserviço prestado pela empresa assolada pela insuficiência de meios de pagamento e pela desestruturação".

Assim, o deferimento ou não do processamento do pedido de recuperação judicial deve levar em conta a capacidade do devedor em honrar seus compromissos:

O passivo exigível é o critério econômico determinante para a abertura dos processos de recuperação, que toma por base a escrituração contábil e o passivo do devedor. Se o passivo não estiver a ponto de comprometer as atividades, devese observar o interesse da sobrevivência da empresa (MARZAGÃO, 2007, p. 86).

Importa analisar se a empresa se encontra em estado reversível de dificuldade, ou seja, se a crise de liquidez é temporária e igualmente premente, sob pena de se postergar o resultado inevitável da liquidação, conforme explica Marzagão (2007, p. 85-86). Para identificar a viabilidade, alguns vetores podem ser utilizados, tais como importância social, mão-de-obra e tecnologia empregadas, volume do ativo e passivo, tempo de empresa e porte econômico (COELHO, 2006, p. 383-385). Não havendo viabilidade econômica, não logrará êxito a empresa em seu plano de recuperação. Não havendo viabilidade econômica, não há como manter-se a fonte produtora e os empregos, tampouco cumprir a função social e o estímulo à atividade econômica.

Esse conjunto de implicações positivas geradas pela recuperação empresarial, revela a contundente relação do instituto com os objetivos do desenvolvimento sustentável e com a sustentabilidade empresarial conforme será exposto, pois há relação de afinidade mútua com a concretização de valores e princípios constitucionais relacionados com o desenvolvimento da empresa e da sociedade como um todo.

\section{DO DESENVOLVIMENTO SUSTENTÁVEL À SUSTENTABILIDADE EMPRESARIAL}

A partir da década de 1960 fica mais evidente preocupação com o meio ambiente. O primeiro grande movimento da comunidade internacional contemplando discussões desta natureza resultou na criação do Clube de Roma, que em 1972 publicou o relatório intitulado "Limites do Crescimento", o qual abordava temas cruciais para o futuro da humanidade, como poluição, energia, saneamento, meio ambiente, crescimento populacional.

Também em 1972, a ONU expressou formalmente sua preocupação com os problemas ambientais, realizando em junho daquele ano, em Estocolmo, a Primeira Conferência Mundial sobre o Homem e o Meio Ambiente. Na sequência, em 1984, a Assembleia Geral das Nações Unidas criou a Comissão Mundial sobre o Meio Ambiente e o Desenvolvimento, cujo lema era: "Uma agenda global para a mudança". Após três anos de trabalho, em 1987, a comissão apresentou seu relatório final, intitulado "Nosso futuro comum". 
Referido documento representa um marco teórico na construção do conceito do termo "Desenvolvimento Sustentável", lá definido como sendo aquele que "atende às necessidades do presente sem comprometer a possibilidade de as gerações futuras atenderem a suas próprias necessidades" (CMMAD, 1991, p. 46). Deste então, o termo "Desenvolvimento Sustentável" passou a constar em todos os documentos gerados pela agenda ambiental da ONU - Agenda 21: Programa de Ação Global e a Carta do Rio de Janeiro, em 1992; Rio+5, em 1997; Rio+10, 2002 e a Rio+20, em 2012 (BOFF, 2016, p. 35-36).

Representa, portanto, o paradigma da atual civilização: uma ressignificação do mundo e o caminho para resolver (ou ao menos amenizar) os problemas globais. Deve ser compreendido "como sendo a conciliação entre a preservação do ambiente e desenvolvimento socioeconômico", capaz de criar grandes oportunidades de negócios, harmonizando a geração de lucro com os cuidados ambientais (SOARES, 2016, p. 55).

O economista norte-americano Jeffrey Sachs (2017, p. 14) defende que o lado normativo do Desenvolvimento Sustentável apresenta quatro pilares básicos para uma boa sociedade: “a prosperidade económica; a inclusão e coesão sociais; a sustentabilidade ambiental e a boa governança pelos principais intervenientes sociais, incluindo o Estado e as empresas".

Assim, ao lado do Estado e da Sociedade Civil, as empresas são fundamentais à concretização dos objetivos sustentáveis. O desenrolar dos tempos e a dinâmica dos acontecimentos de um mundo globalizado passaram a exigir uma postura empresarial que ultrapassasse sua funcionalização com intuito social.

Era preciso que a empresa se desenvolvesse sustentavelmente, planejando ações e estratégias que lhe permitissem, de modo integrado, abordar ampla gama de temas, como os relacionados ao meio ambiente, por exemplo. Era necessário que a empresa buscasse planejar o impacto de suas atividades em relação a questões sociais mais abrangentes sem, contudo, descuidar-se dos efeitos desses temas sobre seu lucro (SAVITZ; WEBER, 2007, p. 4). Era preciso que as empresas adotassem a sustentabilidade como uma decisão estratégica.

Entrava em cena a empresa sustentável, entendida como aquela que harmoniza a "busca legítima por lucro - um dos principais motivadores de crescimento econômico - com a necessidade por desenvolvimento que respeite a dignidade da pessoa humana, a sustentabilidade ambiental e o trabalho decente" (BUCKLEY; SALAZAR-XIRINACHS; HENRIQUES, 2012, p. 263).

O britânico John Elkington cunhou nos anos 90 o termo Triple Bottom Line, conhecido como tripé da sustentabilidade: People (capital humano), Planet (capital natural) e Profit (lucro), modelo que considera também o desempenho social e ambiental da empresa, além do econômico.

Entendem Bier e Bassan (2015, p. 149) que empresa sustentável é aquela voltada para o crescimento, rentabilidade, resultados econômicos e, ainda, promoção do desenvolvimento da sociedade e preservação do planeta, referindo-se às três principais dimensões que envolvem a sustentabilidade: ambiental, social e econômica.

Para Savitz e Weber (2007, p. 2), empresa sustentável é aquela que gera lucro para seus acionistas, ao mesmo tempo em que resguarda o meio ambiente e promove melhorias na vida das 
pessoas com quem mantém interações. Assim, seria plenamente possível uma empresa obter lucro ao mesmo tempo em que emprega condutas sustentáveis, transformando a sociedade.

Portanto, a empresa sustentável representa um modelo para o diálogo global sobre o crescimento e o desenvolvimento, mas também para uma discussão mais específica sobre o desenvolvimento de empresas e, dentro disso, oferece um modelo sólido para estruturar o debate sobre regulação e a ação voluntária na esfera dos negócios (BUCKLEY; SALAZAR-XIRINACHS; HENRIQUES, 2012, p. 14). Ética empresarial é, assim um termo muito restrito para o que se trata aqui e diz respeito notadamente às escolhas específicas dos gestores em si (SAVITZ; WEBER, 2007, p. 4).

O florescer de uma empresa sustentável reclama uma grande variedade de fatores, cuja importância relativa pode variar em diferentes estágios de desenvolvimento e em diferentes contextos culturais e socioeconômicos. Todavia, algumas condições são consideradas essenciais, desde que interligadas e mutuamente reforçadas: boa governança, diálogo social, concorrência justa, boa gestão da economia, respeito pelos direitos humanos e pelas normas trabalhistas internacionais, educação regular, técnica e continuada da mão de obra, justiça social e inclusão social (com igualdade de oportunidade de emprego), responsabilidade social corporativa, manejo responsável do meio ambiente, entre outros (BUCKLEY; SALAZAR-XIRINACHS; HENRIQUES, 2012, p. 264). Como se observa, para que uma empresa possa realmente ser considerada sustentável, não basta promover ações isoladas de sustentabilidade e sim, apresentar mudanças efetivas em sua mentalidade.

A visão clássica de uma empresa - aqui entendida como aquela que prestava contas apenas aos seus acionistas - deve ser substituída pelo conceito de empresa sustentável. No mundo contemporâneo, uma empresa que também não contemple seus consumidores, seus fornecedores, seus colaboradores, encontra-se destinada ao insucesso. Não basta apenas focar na qualidade do seu produto ou serviço, mas portar-se de maneira sustentável, comprometendo-se com a comunidade local e com o meio ambiente (LASZLO, 2008, p. 66-67).

Assim, as empresas sustentáveis terão mais sucesso no futuro do que no presente, pois sua prosperidade se propalará por gerações:

As organizações e as sociedades sustentáveis geram rendimentos como fonte de sobrevivência, em vez de consumir o próprio capital, que, nesse contexto, abrange recursos naturais, como água, ar, energia e alimentos, assim, como ativos humanos e sociais - desde o envolvimento dos trabalhadores até o apoio da comunidade - além dos recursos econômicos, como licença de operação, mercado receptivo e infraestrutura legal e econômica. As empresas até podem consumir seu capital durante algum tempo, mas, em geral, não durante muito tempo. Ao contrário, os empreendimentos que honram os princípios da sustentabilidade são duradouros (SAVITZ; WEBER, 2007, p. 2).

O único modo de uma empresa alcançar o sucesso no mundo interdependente de hoje passa pelo caminho da sustentabilidade. Para tanto, faz-se necessário identificar o grupo de pessoas 
que de alguma maneira afetam seu desempenho, as suas ações e as suas decisões (stakeholders), perante os quais seja responsável, com quem desenvolva relacionamentos e em relação aos quais descubra meios de trabalhar em busca de ganhos recíprocos. "A longo prazo, essa situação gerará mais lucro para as empresas e mais prosperidade social, econômica e ambiental para a sociedade" (SAVITZ; WEBER, 2007, p. 3).

Laszlo (2008, p. 113) também pensa assim, ao defender que a sustentabilidade imprime vantagem competitiva à empresa e estimula inovações. "Para atuar dessa maneira no contexto competitivo dos dias atuais, exige-se que as empresas mais expressivas considerem cuidadosamente as dimensões ambientais e sociais de suas atividades de negócios". O grande diferencial de uma empresa reside na abordagem por ela dada a sustentabilidade, social, ambiental e econômica. Quanto mais sustentável uma empresa, mais lucros serão auferidos, resultado de uma gestão empresarial que alia valor econômico e rentabilidade.

E outro não é o pensamento de Souza (2016, p. 257), que traz a sustentabilidade como variável fundamental na gestão empresarial:

Isso implica reforçar o planejamento de longo prazo, mantendo não só a civilização humana com qualidade de vida, mas todo o planeta. É necessário que empresários e dirigentes responsáveis pelas estratégias empresariais (que traduzem em ações concretas) estejam absolutamente convencidos de que o sucesso de seus negócios depende da implementação de uma gestão sustentável.

Portanto, a sustentabilidade empresarial deve ser entendida como atributo intrínseco ao êxito do negócio, como modelo de gestão eficiente na busca de resultados financeiros, sociais e ambientais favoráveis.

\section{SUSTENTABILIDADE E RECUPERAÇÃO DE EMPRESAS: PARALELAS CONVERGENTES?}

A partir dessa perspectiva, constata-se que a recuperação judicial tem por objetivo viabilizar a superação da crise econômico-financeira do devedor. Uma vez exitosa, permite-se a manutenção da fonte produtora, os empregos dos trabalhadores, a satisfação dos interesses dos credores e estimulando-se a atividade econômica. Preserva-se, portanto, a empresa e, consequentemente, sua função social.

Afinal, a empresa não pode mais ser definida como mero instrumento jurídico de atividade lucrativa dos sócios ou meio de remuneração dos trabalhadores. Seu conceito moderno ultrapassa tais contornos para alçá-la como "peça fundamental da atividade produtiva nacional e um decisivo elemento, quer de economia regional, quer da vida local" (PERIN JUNIOR, 2009, p. 128-129). Sua retirada do mercado "representa verdadeira agressão ao equilíbrio social, de que o Estado não poderá desinteressar-se" (PERIN JUNIOR, 2009, p. 128-129).

Para Tomazette (2014, p. 46), é importante registrar que "o maior número de interesses 
circundando a empresa justifica maiores esforços na busca da recuperação, pois o encerramento de uma empresa socialmente importante gera muitos ônus". Neste diapasão, a princípio, toda Empresa economicamente viável é recuperável, entretanto, é alta a taxa de insucesso dos procedimentos pré-insolvenciais.

No Brasil, a lei de recuperação judicial entrou em vigor em junho de 2005 e, durante seus treze anos de vigência, se apresentou pouco frutífera. Estudos realizados por órgãos creditícios ${ }^{4}$ apontam que apenas uma em cada quatro empresas que ingressam com o pedido de recuperação judicial logra êxito nesta empreitada ${ }^{5}$ A resposta para o insucesso, na grande maioria das vezes, reside na demora da empresa em identificar a iminência da crise. Quase sempre o estado de crise apenas é detectado quando já comprometidas as chances de superá-la.

Portanto, faz-se necessário ir além da mera utilização dos meios recuperacionais para salvaguarda do negócio. $\mathrm{O}$ alcance de resultados adequados em procedimento dessa envergadura requer uma mudança cultural de prevenção da crise,

[...] uma maior conscientização da necessidade de uma gestão estratégica e inteligente, orientada para a perenização da empresa; da permanente necessidade de sua modernização e fortalecimento; reinvestindo suas riquezas operacionais para aumentar seu diferencial competitivo, e não, sangrá-la. Requer a adoção de uma consciência preditiva e preventiva, uma mudança de comportamento e atitude (QUEIROZ, 2006, p. 7-20).

A sustentabilidade aparece, assim, como um objetivo a ser buscado pela empresa, a fim de protegê-la em momentos de crise, pois mesmo empresas sustentáveis podem enfrentar intempéries financeiras. Mesmo empresas que apresentam resultados financeiros, sociais e ambientais adequados não se encontram imunes às adversidades do mercado, considerando a dinâmica própria que rege o mundo dos negócios.

Com efeito, ainda que não apresentem problemas de gestão, pode a empresa sofrer os efeitos de crises econômicas que se projetam sobre o sistema da economia de mercado. Questões afetas à desregulamentação do mercado financeiro, aliadas à abertura descriteriosa de linhas de crédito bastam para solavancar a economia. Citem-se, ainda, causas acidentais, como a desvalorização da moeda nacional e conflitos sociais.

Todavia, se atingidas pela crise econômico-financeira, sua postura sustentável permitirá

4 Estudo inédito do birô de crédito Serasa Experian acompanhou 3.522 empresas que tiveram a recuperação judicial deferida entre junho de 2005 - ano em que a lei for criada - a dezembro de 2014 (SERASA EXPERIAN, 2018). Desse número, 946 companhias tiveram o processo encerrado no período. Delas, apenas 218 (ou $23 \%$ ) voltaram à ativa. A realidade para as demais 728 foi ter a falência decretada (BRANT, 2019).

5 A título de comparação, na Comarca de Brusque/SC, deste a vigência da lei 11.1101/05, ingressaram 11 pedidos de Recuperação Judicial. Destes, 01 foi indeferido; 02 pediram desistência e 05 foram convolados em falência (diante do não cumprimento do plano de recuperação), o que provavelmente ocorrerá em relação aos demais feitos ainda em tramitação, considerando a dificuldade de cumprir-se os compromissos acordados no pacto recuperacional. Apenas um processo foi finalizado com o cumprimento do plano de reestruturação, embora a empresa recuperanda tenha diminuído consideravelmente suas atividades deste então, pois o plano de recuperação incluía a venda de seus imóveis e do parque fabril. Atualmente, a empresa desenvolve suas atividades em imóvel locado e sua produção não atinge $15 \%$ do volume movimentado antes do procedimento pré-falencial. Disponível em Sistema de Automação Judiciário - SAJ. 
que o desequilíbrio seja detectado em seus primeiros sinais, possibilitando o manejo dos instrumentos recuperacionais no momento oportuno, quando ainda capazes de produzir efeitos positivos. Além disso, sua postura sustentável ampliará o leque de medidas recuperacionais de que poderá utilizar-se.

Nesse sentido, cite-se, por exemplo, a comercialização de créditos de carbono mediante a emissão de Certificados de Emissões Reduzidas - CERs. Com a ratificação pelo Brasil do Protocolo de Kioto (Tratado Internacional de Compromisso de Redução de Poluentes no Meio Ambiente), afigura-se perfeitamente viável e factível que sociedades empresárias possam comercializar os chamados CERs, conhecidos como certificados de crédito de carbono. Uma empresa em recuperação portadora de tais certificados poderá negociá-los no mercado, ampliando suas possibilidades de captar ativos financeiros (GUERRA, 2016, p. 206).

Deste modo, uma empresa com conduta sustentável provavelmente também terá maior êxito na contratação de um seguro-caução como forma de garantir o cumprimento das obrigações previstas no plano e evitar a convolação da recuperação em falência. Se bem utilizado, de forma específica para atender o devedor em crise econômico-financeira, poderá se transformar em potencial meio de recuperação (GUERRA, 2016, p. 208).

Considere-se, ainda, que uma empresa que tenha se preocupado com a dimensão social da sustentabilidade, mantendo relações saudáveis com seus colaboradores, fornecedores e a sociedade em geral, por certo contará com a boa vontade destes na execução do plano de recuperação. $\mathrm{O}$ comprometimento dos empregados, bem como a confiança dos credores influenciará positivamente na consecução do pacto de reestruturação.

Assim, prever a crise e dispor de antemão de planos de reestruturação são medidas que se coadunam com o conceito de empresas sustentáveis. A solução, via de regra, encontra-se dentro da própria empresa, desde que as medidas sejam tomadas no momento adequado. Embora a superação da crise econômico-financeira seja o objetivo finalístico dos institutos recuperacionais, nada impede que sejam utilizados de forma antecipada, diante da iminência de uma crise.

Tomazette (2014, p. 47) entende que o objetivo geral da recuperação é a superação da crise ou sua prevenção, “embora o texto da Lei não pareça ter esse objetivo, a lógica impõe que se reconheça essa possibilidade, pois não há dúvida de que se a crise é evitável, é muito melhor impedi-la de começar do que deixá-la acontecer, para só então solucioná-la”.

Isto posto, é na atuação sustentável e preventiva que a recuperação terá maiores chances de tornar-se exitosa. É na iminência da crise que os gestores devem mobilizar-se para o ingresso de medidas que visem evitar a falência da empresa. Caso contrário, quando já instalada a situação crítica, dificilmente se terá sucesso. Nesse contexto, a empresa sustentável encontra-se melhor preparada para superar uma crise financeira a partir dos mecanismos recuperacionais, a fim de permanecer no mercado. Todavia, é possível manter-se sustentável durante o procedimento de recuperação?

A sustentabilidade deve ser compreendida, portanto, como um critério normativo para a reconstrução da ordem econômica, como uma condição para a sobrevivência humana e um suporte 
para se chegar a um desenvolvimento duradouro, questionando as próprias bases da produção (LEFF, 2011, p. 15).

\section{CONSIDERAÇÕES FINAIS}

A partir das reflexões expostas, é possível afirmar que são os ideais sustentáveis que guiarão as relações econômicas no futuro. O desenvolvimento sustentável e de qualidade encontrase consubstanciado na prosperidade econômica, na preservação ambiental, na inclusão social. Neste sentido, ressaltam Okafor e Ibietan (2019), acerca do conceito de desenvolvimento sustentável:

[...] development that meets the needs of the present without compromising the ability and capacity of future generations to meet their own needs. Sustainable development is manifest in different nuances and in different translations: the Norwegian emphasis is on "bearing capacity", the English translation highlights durability and conservation, the Polish refers to balanced development and in some other languages it means "balanced householding." These translations have one thing in common, they point to "restraint" and "balance".

A grande maioria dos países do mundo preocupa-se com a consecução destes objetivos, mesmo aqueles que desconhecem a realidade "abaixo da linha da pobreza" e cumprem suas obrigações com o meio ambiente, pois não há limites territoriais que possam barrar os efeitos de uma crise humanitária ou da degradação ambiental. A sustentabilidade reclama igualdade de oportunidades, capital circulante, acesso ao mercado de trabalho, dentre outras demandas.

Ao lado do Estado e da sociedade civil, as empresas são fundamentais à concretização da sustentabilidade. Contudo, para além de cumprir seu papel no caminho do desenvolvimento sustentável, é justamente a conduta sustentável da empresa que poderá lhe conferir efetividade, principalmente quando se utilizar dos instrumentos recuperacionais, cada vez mais em voga diante da instabilidade econômica dos tempos modernos.

A sustentabilidade afigura-se, portanto, como critério normativo ao êxito de uma empreitada recuperacional, vez que a realidade tem demonstrado que, apenas a existência de instrumentos jurídico-econômicos para tal fim, são insuficientes para superar a crise. Embora toda a empresa possa ser recuperável, o êxito do plano de reestruturação encontra-se diretamente associado ao momento adequado da percepção da crise. A grande maioria das empresas demora a identificar seu estado de crise ou, identificando-o, tarda ou perde o momento adequado à busca das soluções, o que a leva diretamente à sucumbência.

Portanto, a prevenção da crise ainda é o caminho mais econômico e, certamente, mais seguro de uma empresa obter êxito em se recuperar. E, atentos aos sinais de alerta, os gestores devem buscar ajuda tão logo identificada a situação crítica. A falha, entretanto, não pode ser atribuída apenas à rigidez da norma ou ao engessamento da máquina judiciária.

Culturalmente, somente depois de instalada a crise na empresa é que seus gestores se 
desacomodam. Parte disso deve-se, também, à ideia de soerguimento acompanhada de desvios intencionais de postergação das dívidas e não previsão de manutenção da empresa de forma sustentável a médio e longo prazo.

Afigura-se, portanto, inevitável o declínio das empresas sem gestão eficiente e sustentável. Nenhum instrumento de reestruturação jurídico-econômico servirá como "medida de cura" para uma empresa inviável. Neste cenário, a empresa que adotou postura sustentável por certo lograra êxito na atuação preventiva, bem como disporá de maiores meios para recuperar-se.

Registre-se que a recíproca também é verdadeira, à medida que os mecanismos de reestruturação de empresas contribuem para o equilíbrio da sustentabilidade, pois o encerramento das atividades de uma empresa compromete o desenvolvimento sustentável. Isto pois os efeitos da quebra de uma empresa não ficam adstritos à suas relações contratuais, vez que não se trata de um mero fato da vida comercial.

O aumento do número de desempregados gera sequelas não só econômicas, mas também sociais e psicológicas. O encerramento das atividades faz cessar o recolhimento de tributos, comprometendo a execução das políticas públicas por parte do Estado. Indiretamente, ainda, aumenta a criminalidade e compromete a segurança pública, o sistema de saúde, a educação. Considere-se, ainda, a diminuição da concorrência, com potencial abuso de posição dominante pelos concorrentes remanescentes.

Ademais, eventual concentração de mercado pode refletir no aumento do preço dos produtos/serviços desenvolvidos pela empresa extinta. Tais ocorrências fomentam a exclusão social, as desigualdades e comprometem o mínimo existencial. Acrescente-se a isso a degradação ambiental, resultado da deterioração do parque fabril e do tratamento inapropriado dos resíduos industriais.

Portanto, a quebra de uma empresa produz reflexos de toda ordem: econômicos, sociais, ambientais, os quais comprometem o desenvolvimento da comunidade em que se encontrava inserida. Compromete, assim, o desenvolvimento sustentável, conceito esse primordial à nossa época. Há quem defenda que, "no fundo, a expressão 'desenvolvimento sustentável' é um valor similar ao seu mais nobre antepassado, a justiça social" (VEIGA, 2010).

Por outro lado, os instrumentos recuperacionais, ao oportunizarem a superação da crise econômico-financeira, permitem não só o pagamento dos credores; permitem a manutenção da fonte produtora, o emprego dos trabalhadores, o estímulo à atividade econômica. Preservam a empresa e sua função social. Ou seja, muito além de possibilitarem a quitação das dívidas pela empresa devedora, revelam-se verdadeiros instrumentos capazes de perfectibilizar a justiça social.

Por fim, tem-se que recuperação de empresas e sustentabilidade contemplam, ambas, o bem-estar coletivo, caminhando no mesmo sentido. São trilhas que, em algum momento do seu trajeto, confluem na mesma direção, contribuindo ampla e mutuamente ao desenvolvimento socioeconômico das empresas e da sociedade como um todo. 


\section{REFERÊNCIAS}

ARAÚJO, José Francelino. Comentários à lei de falências e recuperação de empresas. São Paulo: Saraiva, 2009.

BIER, Fernanda; BASSAN, Dilani Silveira. Responsabilidade social e ambiental: um estudo de caso em uma empresa de tecnologia em Porto Alegre. Colóquio: Revista do Desenvolvimento Regional - Faccat, Taquara, v. 12, n. 1, p. 149-164, jan./jun. 2015.

BOFF, Leonardo. Sustentabilidade: o que é - o que não é. 4. ed. Petrópolis: Vozes, 2016.

BOUZON, Emanuel. O código de Hamurabi. 3. ed. Petrópolis: Vozes, 1976.

BRANT, Danielle. Só uma em cada quatro empresas sobrevive após recuperação judicial. Bicalho, São Paulo, 2019. Disponível em: https://www.bicalho.com/so-uma-em-cada-quatroempresas-sobrevive-apos-recuperacao-judicial/. Acesso em: 1 jan. 2020.

BRASIL. Lei n. 11.101, de 9 de fevereiro de 2005. Regula a recuperação judicial, a extrajudicial e a falência do empresário e da sociedade empresária. Brasília, DF: Presidência da República, 2005. Disponível em: http://www.planalto.gov.br/ccivil_03/_ato2004-2006/2005/lei/ 111101.htm. Acesso em: 1 jan. 2020.

BUCKLEY, Graeme; SALAZAR-XIRINACHS, José Manuel; HENRIQUES, Michael. A promoção de empresas sustentáveis. Curitiba: Editora Intersaberes, 2012.

CLARO, Carlos Roberto. Recuperação judicial: sustentabilidade e função social da empresa. São Paulo: LTr, 2009.

CMMAD - COMISSÃO MUNDIAL SOBRE MEIO AMBIENTE E DESENVOLVIMENTO. Nosso futuro comum. 2. ed. Rio de Janeiro: Editora da Fundação Getúlio Vargas, 1991.

COELHO, Fábio Ulhoa. Curso de direito comercial. 6. ed. São Paulo: Saraiva, 2006. v. 3.

FAZZIO JÚNIOR, Waldo. Lei de falência e recuperação de empresas. 7. ed. São Paulo: Atlas, 2015 .

GUERRA, Luiz. Da abordagem econômica à lei da recuperação de empresas. In: GRAU, Eros Roberto; SABOYA, Cláudia Maria Martins; ABRÃO, Carlos Henrique (org.). O direito dos negócios. São Paulo: Malheiros, 2016.

LASZLO, Chris. Valor sustentável: como as empresas mais expressivas do mundo estão obtendo bons resultados pelo empenho em iniciativas de cunho social. Rio de Janeiro:

Qualitymark Editora, 2008.

LEFF, Enrique. Saber ambiental: sustentabilidade, racionalidade, complexidade e poder. 8. ed. Petrópolis, RJ: Vozes, 2011.

LIMA, João Batista de Souza. As mais antigas normas de direito. 2. ed. Rio de Janeiro: Forense, 1983. p. 646-647.

LOBO, Jorge. Artigos 35 a 69. In: ABRÃO, Carlos Henrique; TOLEDO, Paulo Fernando 
Campos Salles (coord.). Lei de recuperação de empresas e falência. 3. ed. São Paulo: Saraiva, 2009.

MACHADO, Rubens Approbato. Visão geral da nova Lei 11.101, de 09 de fevereiro de 2005, que reforma o Decreto-lei 7.661, de 21.06.1945 (Lei de Falências), e cria o Instituto da Recuperação Judicial. In: MACHADO, Rubens Approbato (coord.). Comentários à nova lei de falências e recuperações de empresas. 2. ed. São Paulo: Quartierlatin, 2007.

MAMEDE, Gladston. Direito empresarial brasileiro: falência e recuperação de empresas. São Paulo: Atlas, 2006. v. 4.

MARZAGÃO, Lídia Valério. A recuperação judicial. In: MACHADO Rubens Approbato (coord.). Comentários à nova lei de falências e recuperação de empresas: doutrina e prática: lei no 11.101 de 9/2/2005 e LC 118 de 9/2/2005. São Paulo: Quartier Latin, 2007.

OKAFOR, Stephanie C.; IBIETAN, Jide. The Judicial Institution in Nigeria and sustainable development goal 16: a structural functionalist application. International Journal of Innovative Development and Policy Studies, Estonia, v. 7, n. 2, p. 64-79, 2019. Disponível em: http:// seahipaj.org/journals-ci/june-2019/IJIDPS/full/IJIDPS-J-8-2019.pdf. Acesso em: 8 nov. 2019.

PACHECO, José da Silva. Processo de recuperação judicial, extrajudicial e falência. Rio de Janeiro: Forense, 2013.

PASOLD, Cesar Luiz. Metodologia da pesquisa jurídica: teoria e prática. 13. ed. Florianópolis: Conceito Editorial, 2015.

PERIN JUNIOR, Ecio. Preservação da empresa na lei de falências. São Paulo: Saraiva, 2009.

QUEIROZ, Jorge. Prevenção de crises e recuperação de empresas. In: OLIVEIRA, Fátima Bayma (org.). Recuperação de empresas: uma múltipla visão da nova Lei: Lei 11.101/05 de 09.02.2005. São Paulo: Pearson Prentice Hall, 2006.

REQUIÃO, Rubens. Curso de direito falimentar. 15. ed. São Paulo: Saraiva, 1993. v. 1.

SACHS, Jeffrey D. A era do desenvolvimento sustentável. Lisboa: Actual, 2017.

SAVITZ, Andrew W.; WEBER, Karl. A empresa sustentável: o verdadeiro sucesso é lucro com responsabilidade social e ambiental. Rio de Janeiro: Elsevier, 2007.

SERASA EXPERIAN. Pedidos de falências caem 24,9\% no primeiro trimestre. 2018.

Disponível em: https://www.serasaexperian.com.br/sala-de-imprensa/pedidos-de-falencias-caem249-no-primeiro-trimestre-revela-serasa-experian. Acesso em: 4 dez. 2019.

SOARES, Josemar Sidinei. Dignidade e sustentabilidade: fundamentos para uma responsabilidade pessoal, social e jurídica. In: REAL FERRER, Gabriel; DANTAS, Marcelo Buzaglo; SOUZA, Maria Claudia da S. Antunes (org.). Sustentabilidade e suas interações com a ciência jurídica. Itajaí: UNIVALI, 2016. (Coleção Estado, Transnacionalidade e Sustentabilidade).

SOUZA, Maria Cláudia da Silva Antunes. Sustentabilidade corporativa: uma iniciativa de cunho social transformando o meio ambiente. Revista Jurídica, Curitiba, v. 4, n. 45, p. 245-262, 2016. 
TOMAZETTE, Marlon. Curso de direito empresarial: falência e recuperação de empresas. 3. ed. São Paulo: Atlas, 2014. v. 3.

VEIGA, José Eli. Sustentabilidade: a legitimação de um novo valor. 2. ed. São Paulo: SENAC, 2010 .

Como Citar: LANZARINI, Clarice Ana. BODNAR, Zenildo. A sustentabilidade empresarial como criterio normativo à efetividade do instituto da recuperação judicial. Scientia Iuris. Londrina, v.24, n.1, p. 124-141, março 2020. DOI 10.5433/21788189.2020v24n1p124. ISSN 2178-8189.

Recebido em 21/01/2020

Aprovado em 27/02/2020 